\title{
LEITE E ALGUNS DE SEUS DERIVADOS - DA ANTIGUIDADE À ATUALIDADE
}

\section{Zélia Therezinha Custódio Leite*, Delmo Santiago Vaitsman e Paulo Bechara Dutra}

Departamento de Química Analítica, Instituto de Química, Universidade Federal do Rio de Janeiro, CP 68563, 21949-900 Rio de Janeiro - RJ, Brasil

André Guedes

Queijaria Suíça de Nova Friburgo, CP 97322, 28630-250 Nova Friburgo - RJ, Brasil

Recebido em 28/10/04; aceito em 19/9/05; publicado na web em 14/3/06

\begin{abstract}
MILK AND SOME OF ITS DERIVATIVES - FROM ANTIQUITY TO THE PRESENT TIME. This work presents a little of the history which marked the development of the dairy industry in Brazil and in the world. It shows problems and solutions related to the preservation of milk. In general, it also describes the traditional manufacture of cheese and applications of membrane technology as an auxiliary tool in the processing of some types of cheese.
\end{abstract}

Keywords: milk; cheese; membrane.

\section{INTRODUÇÃOO}

De modo semelhante a muitas situações relatadas na história, o acaso e a necessidade de sobrevivência, certamente, fizeram com que o homem identificasse, ainda na antiguidade, a importância do leite e de, pelo menos, dois de seus derivados, a manteiga e o queijo, como importantes fontes nutricionais. A utilização destes três produtos pelas civilizações mais antigas está comprovada em pelo menos cinco citações no Antigo Testamento: Gênesis 18:8, $1^{\circ}$ Samuel 17:18, $2^{\circ}$ Samuel 17:29, Jó 10:10 e Provérbio 30:33¹, mas evidentemente, naquela época ainda não se conhecia uma forma eficiente para conservação do leite. Durante muito tempo o leite foi consumido por quem o produzia e não tinha valor comercial, em virtude de sua rápida deterioração.

Até meados do século XIX, pesquisadores já haviam observado a ocorrência da fermentação em alguns produtos, mas não tinham fundamentos para provar a hipótese de que seres vivos participavam do processo fermentativo. Para explicar, por ex., o fato do vinho avinagrar e da cerveja azedar, na época um problema na indústria de bebidas, Louis Pasteur, considerado o "expert" em fermentação da Universidade de Lille, foi consultado. Descobriu, então, que a acidificação do vinho ocorria devido à presença de microorganismos vivos no ar, que não eram gerados espontaneamente pela bebida e que não resistiam a um aquecimento de $60{ }^{\circ} \mathrm{C}$. Esta hipótese de que seres vivos participavam do processo fermentativo foi comprovada por Pasteur, a partir de 1863, com seus trabalhos sobre vinho e cerveja $^{2}$. Através de experimentos com microorganismos, Pasteur negou a teoria da geração espontânea pela qual ratos podiam ser obtidos a partir da mistura de trapos e pedaços de queijo ${ }^{3}$. A partir de suas observações estabeleceu o processo que ficou conhecido como pasteurização, no qual as bactérias são eliminadas pelo aquecimento por alguns minutos, na faixa de temperatura de 50 a $60{ }^{\circ} \mathrm{C}$, seguido por resfriamento brusco, atribuindo-se ao choque térmico a destruição dos microorganismos em geral ${ }^{3}$. A contribuição decisiva de Pasteur neste campo da ciência pode ser considerada o início da biologia moderna, e resultou em novos caminhos para utilização de certas espécies microbianas benéficas e procedimentos para evitar as prejudiciais ${ }^{4} \mathrm{O}$ processo de pasteurização não foi empregado ime-

*e-mail: leite@iq.ufrj.br diatamente no leite, pois foi necessário aguardar o desenvolvimento do sistema de refrigeração. Portanto, a combinação da pasteurização com a maior utilização da refrigeração industrial, no final do século XIX, permitiram assegurar leite isento de microorganismos prejudiciais à saúde e a disponibilidade de uma maneira eficiente para sua conservação ${ }^{5}$.

As contribuições de Pasteur para a ciência despertaram a admiração mundial. O Brasil se fez presente através do imperador D. Pedro II que, por ser profundamente interessado pelas ciências em geral, teve encontros com o cientista, trocou correspondência e financiou algumas de suas pesquisas quando da fundação do Instituto Pasteur em Paris ${ }^{6}$.

\section{ORIGEM DO LEITE BOVINO NO BRASIL}

Há registros de que os bovinos, para suprir a necessidade de leite e carne, foram introduzidos no Brasil por Martim Afonso de Souza e sua mulher Ana Pimentel após 1531, na capitania de São Vicente, quando da $1^{\text {a }}$ expedição colonizadora enviada por D. João III, rei de Portugal $^{7}$. Consta que em 1535, o donatário de Pernambuco, Duarte Coelho, tenha levado bovinos para o nordeste, enviando algumas cabeças para a Bahia. Em 1550, Tomé de Souza, após ter fundado Salvador, na Bahia, onde instalou a capital do Brasil colonial, mandou buscar em Cabo Verde um lote de bovinos. Acredita-se que destes pontos geográficos o rebanho bovino tenha se espalhado pelo Brasil, dando origem às fazendas de gado que mais tarde se transformaram em povoados e vilas. Data do século XVIII a criação das primeiras fazendas regulares de gado bovino no Brasil.

Os senhores de engenho, em várias regiões do Brasil, possuíam fazendas com criação de bovinos que, inicialmente, foram utilizados no trabalho do campo e nos engenhos de açúcar ${ }^{7}$. No final do século XIX, novas raças de bovinos foram introduzidas no país, sendo que em 1893 foram importados exemplares selecionados da raça zebu. Nessa época a produção de leite e carne atendia ao consumo interno, e o couro, de maior valor, era exportado ${ }^{8}$.

\section{LATICÍNIOS NO BRASIL}

A crescente necessidade mundial de consumo de carne no início do século XX tornou o Brasil um dos países mais procurados 
para a exportação deste produto. Surgiram nessa época imensos matadouros e frigoríficos nos estados de São Paulo e Rio Grande do Sul. Com o crescimento do rebanho ocorreu um aumento da produção de leite, que não era inteiramente aproveitada devido às condições desfavoráveis de transporte. Esta produção adicional foi, então, aproveitada na fabricação de manteiga e queijos pela dificuldade, devido à $1^{\mathrm{a}}$ Grande Guerra, em importar estes produtos $^{8}$

Há registros de que a primeira fábrica de laticínios da América do Sul foi fundada por volta de 1888, na Serra da Mantiqueira, em Minas Gerais, pelo Dr. Carlos Pereira de Sá. Para esta instalação importou maquinário e mão-de-obra especializada da Holanda ${ }^{8}$. Após o surgimento em outros estados de novas fábricas deste setor, sentiu-se a necessidade de divulgação do que vinha sendo feito no Brasil na área de laticínios. Isto foi feito em 1925, quando da realização da $1^{\text {a }}$ Conferência Nacional de Leite e Laticínios realizada no Rio de Janeiro. Nesta conferência, procurou-se enfatizar a importância do leite para a saúde, o valor dos métodos científicos e técnicos aplicáveis à sua industrialização e seus derivados, bem como os métodos mais eficientes para prevenir doenças relacionadas com a saúde pública que atacavam o gado leiteiro. Falou-se, também, do rápido crescimento da indústria de laticínios no Brasil principalmente nos estados de Minas Gerais, São Paulo, Rio de Janeiro e Santa Catarina, apesar das poucas aparelhagens adequadas existentes ${ }^{8}$. Durante essa conferência, aproveitou-se para fazer uma campanha educativa sobre higiene na indústria laticinista. Para tanto, foram encomendados nos Estados Unidos cartazes, filmes e coleções. No Brasil foram feitas oito frases ilustrativas sobre o leite e quinze quadros aquarelados sobre saúde e leite, pelo pintor Mario Tullio. Foi também encenada uma pequena comédia intitulada "Atrás do pote do leite", representada por alunos do então Instituto La-Fayette, no Teatro do Pavilhão Português ${ }^{8}$.

A partir deste evento, tem-se procurado melhorar a qualidade microbiológica do leite através da manutenção de rebanho saudável e ações efetivas de boas práticas de higiene, manuseio do leite, durante e após a ordenha, e, na higienização correta dos equipamentos e utensílios utilizados. Atualmente, já existe a conscientização, pela maioria dos produtores, da importância de se promover o resfriamento do leite na faixa de zero a $4{ }^{\circ} \mathrm{C}$, no máximo 2 $\mathrm{h}$ após a ordenha. Através destes recursos, é possível manter a qualidade microbiológica do leite por até $72 \mathrm{~h}^{9}$. Mesmo com todas as boas práticas, devido à sua própria natureza e composição, o leite não deixa de ser um excelente meio para multiplicação de microorganismos. Portanto, não é possível garantir leite cru com ausência total de bactérias, justificando-se o uso da pasteurização para destruir os patógenos e impedir a proliferação de bactérias, embora alguns microorganismos, como os termofílicos, sejam resistentes a este processo. Hoje, existem outras técnicas utilizadas com o mesmo objetivo da pasteurização. Podem ser citadas a bactofugação, realizada em uma centrífuga especial, hermética, capaz de separar o leite das bactérias e esporos, e a microfiltração onde o leite é filtrado através de membranas com porosidade capaz de reter as bactérias indesejáveis ${ }^{9}$.

Com o progresso da ciência tem sido possível melhorar a tecnologia da indústria de laticínios no Brasil. As modificações no processo de pasteurização do leite, as novas técnicas para eliminação de microorganismos, o desenvolvimento de coalhos de origem vegetal e microbiana ${ }^{9}$, a revolução industrial de maquinários em geral, com a diversidade de equipamentos, a melhoria da qualidade do rebanho, e, a adoção de boas práticas de higiene, desde a ordenha até as diferentes etapas do processamento industrial, para obtenção dos produtos desejados, formam um conjunto que assegura leite e derivados de qualidade.

\section{EFICIÊNCIA NO PROCESSO DE PASTEURIZAÇÃO}

Após as descobertas de Pasteur sobre fermentação e pasteurização em 1863, outras combinações tempo-temperatura de aquecimento, durante o processo de pasteurização do leite, foram investigadas e propostas. Segundo Pelczar et al. ${ }^{10}$ as relações originais de tempo e temperatura de pasteurização foram obtidas com o Mycobaterium tuberculosis, considerado como o agente patogênico mais termoresistente capaz de ocorrer no leite. Esta bactéria é destruída quando exposta a uma temperatura de $140{ }^{\circ} \mathrm{F}\left(60{ }^{\circ} \mathrm{C}\right)$ durante $10 \mathrm{~min}$. Mais tarde foi descoberto que a Coxiella burnetii, agente etiológico da febre Q, transmissível pelo leite, pode sobreviver em alimento aquecido a $143{ }^{\circ} \mathrm{F}\left(61,7^{\circ} \mathrm{C}\right)$ durante $30 \mathrm{~min}$. Como resultado destas descobertas, foram estabelecidas as atuais temperaturas de pasteurização em níveis mais elevados e condições de tempo e temperatura apenas o suficiente para destruir o maior número possível de microorganismos nocivos à saúde, sem modificar significativamente as propriedades e a composição do leite ${ }^{10}$.

Atualmente, a pasteurização continua como importante recurso industrial, sendo realizada nas formas lenta, tipo batelada, "Low Temperature Large Time" (LTLT) e na rápida - "High Temperature Short Time" (HTST). A do tipo LTLT consiste em aquecer o leite a 62- $63{ }^{\circ} \mathrm{C}$ e mantê-lo nesta temperatura por 30-35 min, seguido por resfriamento brusco a $5{ }^{\circ} \mathrm{C}$ ou menos ${ }^{11}$. A rapidez no resfriamento é importante, pois a lentidão nesta fase pode favorecer um aumento considerável de bactérias. Durante o tempo de aquecimento, o leite deve ser agitado para evitar aderências às paredes do recipiente, promover aquecimento uniforme de todas as suas partículas e, ao mesmo tempo, evitar a formação de espuma. Este processo é usado em pequenas indústrias onde o volume de produção não justifica a aquisição de um pasteurizador de placas. Apresenta, contudo, a desvantagem de ser um processo demorado, descontínuo, com operação manual e com possibilidade de desenvolver microbiota termófila na espuma.

A pasteurização do tipo HTST consiste em aquecer o leite a $72{ }^{\circ} \mathrm{C}$ e mantê-lo por $15 \mathrm{~s}$ em um equipamento com trocadores de calor de placas, seguido de choque térmico semelhante ao usado na pasteurização tipo batelada ${ }^{11}$. A pasteurização HTST é o processo mais usado em indústrias de médio e grande porte. Apresenta como desvantagens o alto custo de aquisição e manutenção do equipamento, mas tem as vantagens de ser um processo contínuo, de controle mais eficaz, de maior rapidez, menor área para instalação, menos perdas por evaporação, maior eliminação de termófilos e economia de mão-de-obra.

Em ambos os tipos de pasteurização, a combinação tempo-temperatura é determinada em função da destruição da totalidade das bactérias patogênicas que, freqüentemente presentes no leite cru, possam causar no ser humano a tuberculose e, ainda, a brucelose, doença que contribui para a infertilidade e processos abortivos, entre outras.

\section{EFEITOS DA PASTEURIZAÇÃO NO PROCESSAMENTO DE QUEIJOS EM GERAL}

Com o processo de pasteurização ocorre a destruição de inúmeras bactérias patogênicas e láticas, além da perda de aproximadamente 1/3 do cálcio solúvel na forma de paracaseínato de cálcio. Como as bactérias láticas têm a função de promover a acidificação adequada no processo de fabricação de queijos em geral, há necessidade de se recompor estas bactérias, através da adição de fermento lático ao leite pasteurizado. Segundo Oliveira ${ }^{12}$ essa acidificação é pequena, geralmente, de 1 a $4{ }^{\circ} \mathrm{D}$ (grau Dornic), ou cerca de 0,1 a 0,3 unidades de $\mathrm{pH}$, mas mesmo assim tem um efeito marcante na ação do coalho, o qual tem seu poder coagulante aumentado. Além de 
ajudar na ação da renina, principal enzima presente no coalho e responsável pela coagulação da caseína presente no leite, a acidificação aumenta a consistência do coágulo, auxilia na dessora da massa, que se transformará em queijo, e impede o crescimento de bactérias indesejáveis. Além da acidez, os fermentos láticos, quando associados a certas culturas de microorganismos com propriedades lipolítica e proteolítica, como por ex. Penicillinium roqueforti e Pennicillinium camembert, conferem sabor e aromas típicos na etapa de maturação dos queijos roquefort e camembert ${ }^{12}$. Há necessidade, também, de se fazer reposição do cálcio solúvel, na forma de cloreto de cálcio a $50 \%$, pois este participa do processo de coagulação da massa, que se tornará queijo, evitando que sua consistência fique muito mole. Então, a adição de fermento lático e cálcio solúvel ao leite pasteurizado são recursos utilizados para contornar problemas decorrentes da pasteurização, durante os processos de fabricação de queijos frescos em geral.

\section{LATICÍNIOS - FORMAÇÃo DE MÃo DE OBRA ESPECIALIZADA NO BRASIL}

Em relação à formação de mão-de-obra especializada em laticínios, decisivamente há, no Brasil, dois institutos que se destacam, a Queijaria Suíça de Nova Friburgo (QSNF) e o Instituto de Laticínios Cândido Tostes (ILCT). A QSNF começou a ser idealizada em 1985, por iniciativa do Instituto Fribourg, uma sociedade civil, sem fins lucrativos, de caráter cultural, educacional, beneficente e filantrópico. Foi inaugurada em 1987, com recursos suíços (3/4) e nacionais (1/4). O interesse da Suíça pela região de Nova Friburgo começou após divulgação de pesquisas, em 1973, do historiador suíço Martin Nicoulin sobre a saga de seus imigrantes que vieram para o Brasil cumprindo tratado de colonização assinado por D. João VI, rei de Portugal e do Brasil. Após estas divulgações fundaram-se duas associações, uma em Nova Friburgo/Brasil e outra em Fribourg/Suíça. Iniciou-se, desde então, um movimento de intercâmbio entre estas duas cidades que tem como objetivos preservar a memória dos imigrantes suíços fundadores do município e desenvolver a bacia leiteira da região de Nova Friburgo, além da tecnologia de alimentos de origem suíça com alto padrão de qualidade. A QSNF possui registro junto ao Ministério da Agricultura e Inspeção Federal, e recebe em média, da região de Nova Friburgo, 2500 L de leite/dia sendo $2 / 3$ de vaca e $1 / 3$ de cabra $^{13}$.

O ILCT está localizado em Juiz de Fora - MG. Foi inaugurado em 1940, com o nome de Fábrica-Escola de Laticínios Cândido Tostes (FELCT) e tem contribuído na formação de competentes profissionais do ensino médio com especialidade em laticínios. Tanto a QSNF quanto o ILCT promovem anualmente cursos de curta duração que têm como público-alvo pessoas interessadas em adquirir conhecimento teórico-prático sobre laticínios em geral.

Em 1974, o Governo do Estado de Minas Gerais autorizou a constituição da Empresa de Pesquisa Agropecuária de Minas Gerais -EPAMIG que incorporou o ILCT com todas as suas atividades e patrimônio. Como o objetivo da EPAMIG era de responder pelas atividades de pesquisa no estado, o ILCT também passou a desempenhar esta atividade, contribuindo para o aprimoramento técnico da área de laticínios ${ }^{14}$.

\section{MEMBRANAS - ACOMPANHANDO A EVOLUÇÃO}

As membranas naturais são conhecidas desde a antiguidade, mas o desenvolvimento e as principais aplicações de processos de separação com membranas sintéticas, em escala de laboratório, teve início em 1920. Na Tabela 1, está incluído o processo de produção de queijos desenvolvido na França por Mauboi, em 1969.

\section{APLICAÇÃO DE MEMBRANAS NA INDÚSTRIA DE LATICÍNIOS}

Os processos de filtração por permeação com membranas são usados para efetuar uma variedade de separações e podem ser definidos como barreiras seletivas ao transporte de massa de certos componentes de uma amostra. A distinção entre as técnicas de filtração clássica e as de filtração com membranas de MF e UF é que estas apresentam poros menores e, por isto, oferecem maior resistência à separação dos solutos componentes da solução. Para forçar a passagem de um ou mais solutos da solução e, conseqüentemente, promover a separação é necessário aumentar a pressão de operação à medida que se caminha da MF para a UF a fim de se obter fluxos economicamente viáveis. A fase que atravessa a membrana é conhecida como permeado e a que fica retida pela membrana, que é a fase enriquecida em um ou mais componentes, é chamada de retentado ou concentrado.

Nos processos com membranas há dois tipos de filtração, a convencional e a tangencial. Na filtração convencional o fluido escoa perpendicularmente através da membrana filtrante e na tangencial, o escoamento é paralelo à área da membrana. Este último tipo de sistema de filtração, largamente utilizado em processamento do leite e soro de queijo é mais eficiente, pois facilita o arraste dos solutos, evitando que estes se acumulem sobre a superfície da membrana ${ }^{16}$.

Tabela 1. Principais aplicações dos processos de separação com membranas. Adaptada da ref. 15

\begin{tabular}{|c|c|c|c|}
\hline Processos & País & Ano & Aplicação \\
\hline Microfiltração* & Alemanha & 1920 & Laboratório \\
\hline Ultrafiltração* & Alemanha & 1930 & Laboratório \\
\hline Hemodiálise $^{*}$ & Holanda & 1950 & Rim artificial \\
\hline Eletrodiálise $^{\#}$ & Estados Unidos & 1955 & Dessalinização \\
\hline Osmose reversa ${ }^{\#}$ & Estados Unidos & 1960 & Dessalinização água mar \\
\hline Ultrafiltração ${ }^{\#}$ & Estados Unidos & 1960 & Concentração de macromoléculas \\
\hline UF de leite\# & França & 1969 & Produção de queijos \\
\hline Separação Gás\# & Estados Unidos & 1979 & Recuperação de hidrogênio \\
\hline Destilação Membrana* & Alemanha & 1981 & Concentração de soluções aquosas \\
\hline Pervaporação ${ }^{\#}$ & Alemanha/Holanda & 1982 & Desidratação de substâncias orgânicas \\
\hline Nanofiltração* & Estados Unidos & $1980 \mathrm{~s}$ & $\begin{array}{l}\text { Separação de solutos baixo PM do solvente } \\
\text { (sais inorgânicos) }\end{array}$ \\
\hline
\end{tabular}

* pequena escala; \# escala industrial 
Os processos de separação com membranas estão sendo utilizados desde a década de 70 na indústria de laticínios e usam, principalmente, dois tipos de membranas, as de microfiltração (MF) e ultrafiltração (UF). O princípio de separação destas membranas tem como base a diferença de tamanho dos componentes da solução em relação ao tamanho de poros das respectivas membranas ${ }^{16}$. O tamanho do poro das membranas de microfiltração (MF) é indicado pelo diâmetro médio de poro e é especificado em micrômetro $(\mu \mathrm{m})$. Estas membranas retém partículas em suspensão, que também são especificadas em $\mu \mathrm{m}$, na faixa de 0,10 a $5 \mu \mathrm{m}$. Já para as membranas de ultrafiltração (UF), o tamanho do poro é usualmente referido, através da "massa molecular de corte" (MWCO), cuja unidade mais utilizada é o Dalton. Como o tamanho das proteínas é usualmente expresso em termos de sua massa molecular, tornou-se usual caracterizar membranas de UF em termos de sua capacidade de reter proteínas de determinada massa molecular. O termo "massa molecular de corte" para membranas de UF designa o tamanho da proteína que será retida por uma membrana de determinada eficiência, dependendo da finalidade. A UF retém macromoléculas tais como proteínas ou partículas maiores que 0,001 a $0,02 \mu \mathrm{m}$. No caso da aplicação de processos com membranas de MF ou UF em produtos alimentícios, um dos fatores a ser considerado é a seleção da membrana e outros materiais de contato de modo a atender às orientações higiênicas e de saúde, sendo as de poli(éter-sulfona) as mais utilizadas na indústria de laticínios. Estas membranas apresentam como vantagens suportar temperaturas de até $55^{\circ} \mathrm{C}$ de modo a manter os fluidos com baixa viscosidade, resistir a valores extremos de $\mathrm{pH}$, facilitar a limpeza e sanitização das membranas e, ainda, possibilitar melhor controle do crescimento de microorganismos ${ }^{16}$.

Apesar da tecnologia de membranas de filtração por osmose reversa (OR), do soro de queijo, ter sido a primeira aplicação de sucesso comercial em 1971, a ultrafiltração (UF) é mais utilizada na indústria de laticínios. Pode ser usada para, a partir do soro de queijo, obter concentrado de proteínas, que posteriormente será adicionado a iogurtes, queijos, carnes processadas, alimentos infantis e bebidas. Já a microfiltração (MF) serve para controlar o conteúdo de gordura do soro de queijo antes da UF, e remover microorganismos do leite e do soro de queijo sem necessidade da alta temperatura de pasteurização ${ }^{16}$.

Atualmente a UF é largamente empregada na produção de alguns tipos de queijos a partir do leite pasteurizado, principalmente os macios, conforme mostrado no fluxograma da Figura 1. O processo, utilizando membrana de UF, é baseado no trabalho de Maubois et al. ${ }^{16}$, e difere do tradicional, como mostra o fluxograma da Figura 2, logo no seu início, onde ocorre uma pré-concentração das proteínas do leite pasteurizado, obtendo-se o "pré-queijo" ou retentado que é, então, convertido em queijo pelo processamento tradicional. A pré-concentração inicial leva a um aumento no rendimento da produção de queijo, devido à inclusão das proteínas do soro, com conseqüente decréscimo na geração de resíduos conforme mostra a Tabela 2 .

Tabela 2. Produção de Queijos- Processos Tradicional e com UF (100.000 kg leite/dia). Adaptada da ref. 16

\begin{tabular}{lccc}
\hline Tipo de queijo & $\begin{array}{c}\text { Produção } \\
\text { processo } \\
\text { tradicional }(\mathrm{kg})\end{array}$ & $\begin{array}{c}\text { Produção } \\
\text { processo } \\
\text { UF }(\mathrm{kg})\end{array}$ & $\begin{array}{c}\text { Produção } \\
\text { extra/dia } \\
(\%)\end{array}$ \\
\hline Feta & 13.700 & 17.800 & 30 \\
Mussarela & 9.930 & 11.750 & 18 \\
Cheddar & 10.360 & 12.290 & 18 \\
Queijo fresco & 11.432 & 14.824 & 30 \\
\hline
\end{tabular}

O fluxograma da Figura 1 corresponde ao procedimento da produção de queijos pelo processo que utiliza membrana de ultrafiltração e o da Figura 2, ao que utiliza o processo tradicional. No primeiro, a estimativa de produção de queijo é de 12 a $19 \%$ e no segundo, de 10 a $15 \%$. O aumento do rendimento no processo, que utiliza membrana de UF, justifica-se pelo aproveitamento total das proteínas, que no processo tradicional permanecem no soro.

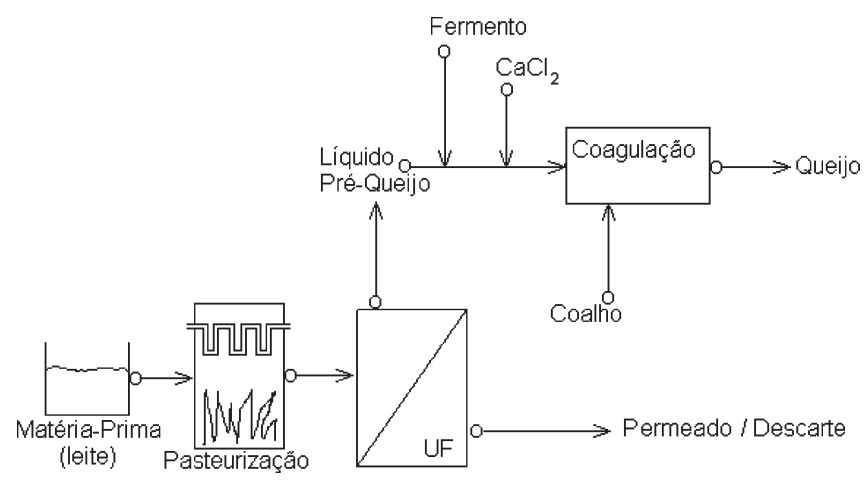

Figura 1. Fluxograma do processo de produção de queijo com utilização membrana de UF. Adaptado da ref. 16

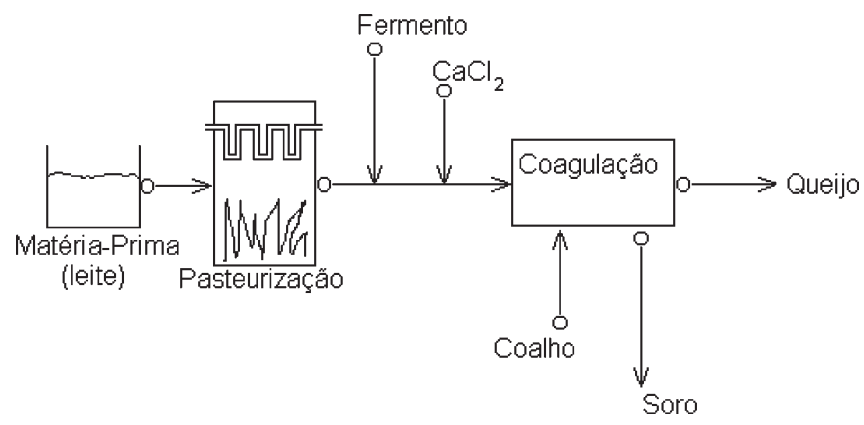

Figura 2. Fluxograma do processo tradicional de produção de queijo. Adaptado da ref. 16

Há registros de que no mundo estão instaladas cerca de 300.000 $\mathrm{m}^{2}$ de área de membranas aplicadas à indústria de laticínios ${ }^{16}$. O Brasil, apesar de ser um país relativamente novo, e que teve sua primeira fábrica de laticínios instalada em 1888, já possui plantas de membranas de ultrafiltração. O queijo Minas Frescal, produzido com auxílio da técnica de ultrafiltração, vem sendo comercializado no Brasil desde 1988, podendo ser encontrado na forma tradicional e também com baixo teor de gordura. Neste tipo de processamento todas as proteínas do leite são aproveitadas, o que permite fazer todo o processo em sistema fechado ${ }^{17}$.

Outras pesquisas, como por ex., o uso de membranas na obtenção de iogurte com baixo teor de lactose, para atender consumidores que apresentam má absorção ou intolerância à lactose, têm sido desenvolvidas $^{18}$.

\section{CONCLUSÃO}

As origens históricas da produção de queijo nos remetem a alguns países da Europa, como França e Suíça, que contribuíram de forma significativa desde as descobertas sobre fermentação e pasteurização até suas técnicas especiais para fabricação de queijos. Conhecer e divulgar estas aquisições, que contribuíram para o desenvolvimento da indústria laticinista tradicional e outras mais 
recentes, como é o caso da tecnologia de membranas é tarefa da maior relevância. A utilização desta tecnologia inovadora na indústria de laticínios tem a vantagem de apresentar melhor aproveitamento das proteínas no processo de produção de queijos, obtendo-se maior rendimento e produzir concentrados de proteínas a partir do soro de queijo resultante do processo tradicional, e eliminar microorganismos sem necessidade de aquecimento. Mas, apesar do sucesso da tecnologia de membrana na área de laticínios, não se deve perder de vista que alguns queijos continuarão a ser processados pela forma tradicional, por conta do domínio da metodologia desenvolvida ao longo de séculos e que, para alguns tipos de queijo, certamente, será sempre insubstituível. Com relação à produção e consumo de queijos no Brasil pode-se dizer que nos últimos anos tem ocorrido aumento substancial devido à modernização da tecnologia, grande preocupação dos indivíduos com a saúde, e, também, pela praticidade de consumo deste alimento fora do domicílio. Atualmente, queijos nacionais, ditos populares - minas, prato e mussarela - possuem processamento tecnológico de extrema qualidade. Alguns queijos considerados finos, como o moleson, reblochon e raclete, produzidos no país, estão cada vez mais semelhantes aos de origem suíça. Entre os franceses, queijos tipo roquefort, camembert e brie são encontrados com marcas nacionais de excelente qualidade. Mas o aumento do consumo destes queijos depende certamente da melhoria do poder aquisitivo da nossa população.

\section{REFERÊNCIAS}

1. Bíblia Sagrada, Antigo Testamento, $2^{\mathrm{a}}$ ed., Ed. Vozes: Rio de Janeiro, 2003.
2. Panek, A. D.; Química para Poetas: Pão e Vinho: A arte e a ciência da fermentação, Casa da Ciência /IQ - UFRJ: Rio de Janeiro, 2001.

3. Vanin, J. A.; Alquimistas e Químicos, $9^{\mathrm{a}}$ ed., Ed. Moderna: São Paulo, 1996, cap. 4.

4. Martin, C.; Laiterie, Encyclopédie Agricole, J.B.Baillière et Fils: Paris, 1920, cap. 1.

5. http://www.google.com, acessada em Junho 2004;

http://www.scholargoogle.com, acessadas em Março 2005.

6. Filgueiras, C. A. L.; Quim. Nova 1988, 11, 212.

7. http://www.orlandocruz.com.br; http://www.probrasil.com; http://www.riogrande.com.br/história, acessadas em Junho 2004.

8. Annaes da $1^{a}$ Conferência de Leite e Laticínios, Rio de Janeiro, 1925; Guedes, A.; Curso de Fabricação de Queijos, Queijaria Suíça de Nova Friburgo/Sebrae: Rio de Janeiro, 1996.

9. Perry, K. S. P.; Quim. Nova 2004, 27, 294.

10. Pelczar, M.; Reid, R.; Chan, E. C. S.; Microbiologia, MacGraw-Hill: São Paulo, 1981, cap. 39.

11. Caballero, B.; Trugo, L. C.; Finglas, P. M.; Encyclopedia of Food Sciences and Nutrition, Academic Press: Oxford, 2003, cap. 6.

12. De Oliveira, J. S.; Queijo: Fundamentos Tecnológicos, $2^{\mathrm{a}}$ ed., Ed. UNICAMP: São Paulo, 1986, cap. 3, 4.

13. Guedes, A.; Fabricação de Queijos, Queijaria Suíça de Nova Friburgo: Rio de Janeiro, 2003.

14. http://www.candidotostes.com.br, acessada em Maio 2004.

15. Mulder, M.; Basic Principles of Membrane Technology, $2^{\mathrm{a}}$ ed., Kluwer Academic Publishers: Dordrecht, 2000, cap. 1.

16. Cheryan, M.; Ultrafiltration and Microfiltration Handbook, Illinois, USA; Technomic Publishing CO: Lancaster, 1998, cap. 1, 3, 6, 8; Zydney, A.L.; Int. Dairy Journal 1998, 8, 243; Farro, P. C. A.; Tese de Mestrado, Universidade Estadual de Campinas, Brasil, 2003.

17. Viotto, L. A; Viotto, W. H; Cunha, C. R.; Resumos do $4^{o}$ Congresso Internacional de Tecnologia de Membranas, Florianópolis, Brasil, 2003.

18. Gigante, M. L; Almeida, T. C. A; Pereira, M. A. G.; Resumos do $4^{o}$ Congresso Internacional de Tecnologia de Membranas, Florianópolis, Brasil, 2003. 